\title{
ESTADO DE EXCEÇÃO, RESISTÊNCIA E VIOLÊNCIA: UM ESTUDO COMPARATIVO A PARTIR DE GIORGIO AGAMBEN E HANNAH ARENDT
}

\author{
STATE OF EXCEPTION, RESISTANCE AND VIOLENCE: A COMPARATIVE STUDY \\ FROM GIORGIO AGAMBEN AND HANNAH ARENDT
}

\author{
Karla Pinhel Ribeiro ${ }^{1}$
}

\begin{abstract}
RESUMO
Dentro da teoria do estado de exceção, podemos dizer que o sistema jurídico do Ocidente apresenta uma dupla estrutura, formada por dois elementos heterogêneos e, no entanto, coordenados: um elemento normativo e jurídico em sentido estrito - a potestas - e um elemento anômico e metajurídico - a auctoritas. O estado de exceção é o dispositivo que deve, em última instância, articular e manter juntos os dois aspectos da máquina jurídico-política, instituindo um limiar de indecibilidade entre anomia e nomos, entre vida e direito, entre auctoritas e potestas. O ponto central do debate filosófico jurídico, tanto no direito de resistência quanto no estado de exceção, quanto ao que está realmente em questão é a existência de uma ação em si extra-jurídica. No plano da filosofia do direito, a questão da resistência consiste em um debate que apresenta duas teses opostas: a de que o direito deve coincidir com a norma e aquela que, em oposição, defende que o âmbito do direito excede a norma, mas que em última análise, as duas posições opostas encontramse solidárias a uma mesma condição, na exclusão da existência de uma esfera da ação humana que escape totalmente ao direito.
\end{abstract}

PALAVRAS-CHAVE: Direito - Estado de Exceção - Democracia - Resistência - Violência

\begin{abstract}
Within the state of exception theory, we can say that the Western legal system has a double structure, formed by two heterogeneous and yet coordinated elements: a normative and legal element in the strict sense - the potestas - and an element anomic and metajuridical - the auctoritas. The state of exception is the device that must, ultimately, articulate and keep together the two aspects of the juridical-political machine, instituting a threshold of indecisively between anomie and nomos, between life and law, between auctoritas and potestas. The central point of the legal philosophical debate, both in the right of resistance and in the state of exception, as what is really at issue is the existence of an action in itself extra-legal. In terms of the philosophy of law, the issue of resistance consists of a debate that presents two opposing theses: that the law must coincide with the norm and the one that, in opposition, defends that the scope of the law exceeds the norm, but that in the

\footnotetext{
${ }^{1}$ Pós-Doutora em Filosofia pela Universidade Federal de Santa Catarina (UFSC). Doutora em Filosofia pela Universidade de São Paulo (USP), Mestre em Filosofia pela Universidade Federal de Santa Catarina (UFSC) e Graduada em Direito pela Universidade Estadual de Londrina (UEL). Professora do Centro Universitário Curitiba (UNICURITIBA). Membro do GT Filosofia e Direito da ANPOF. Lattes:http://lattes.cnpq.br/7479262758658154. ORCID:https://orcid.org/0000-0003-4566-6028. E-mail: karlapinhelribeiro@gmail.com
} 
last analysis, the two opposing positions are found to be united in the same condition, in the exclusion of the existence of a sphere of human action that totally escapes the law.

KEYWORDS: Law - State of Exception - Democracy - Resistance - Violence

\section{INTRODUÇÃO}

O presente artigo buscou apresentar o conceito de estado de exceção trazido pelo debate levantado por Giorgio Agamben a partir de Carl Schmitt sobre as implicações do termo no âmbito jurídico e politico.

Agamben destaca a relação entre exceção e resistência, acerca de uma esfera da ação humana que não seja regulada pelo direito.

Nesse sentido, o conceito de resistência é trabalhado por Hannah Arendt como sinônimo de desobediência civil. A autora tem uma contribuição importante sobre a distinção entre poder (potestas), autoridade (autorictas) e violência.

Assim, na primeira parte, partimos do conceito elaborado por Schmitt, ponto de partida das análises de Giorgio Agamben. Depois, fazemos uma análise da natureza ontológica da resistência e do debate sobre a natureza jurídica/extra-jurídica da resistência e da exceção.

Prosseguimos com a análise da violência e da desobediência civil a partir de Hannah Arendt para propiciar uma perspectiva comparada deste debate jurídico-político.

Ao final, apresentamos a proposta de Arendt de compatibilidade entre a desobediência civil e o direito e a concepção de política arendtiana.

\section{O PONTO DE PARTIDA}

Carl Schmitt em Political Theological: Four Chapters on the Concept of Sovereignty afirma que seria uma distorção da separação entre a sociologia e a jurisprudência a alegação de que a exceção não tenha significado jurídico e por essa razão trata-se apenas de sociologia.

Para Carl Schmitt, a exceção não pode ser subsumida e desafia a codificação geral, ao mesmo tempo que revela a natureza jurídica da decisão em sua absoluta pureza. A exceção aparece em sua forma absoluta quando a situação trazida é a validade da prescrição legal. Segundo Carl Schmitt, toda norma geral demanda uma "normal e cotidiana" forma de vida a qual ela pode ser de fato aplicada e estar sujeita a suas regulações, pois a norma requer um meio homogêneo, a situação de normalidade pertence a sua validade imanente. A situação de uma normalidade efetiva não é uma mera suposição cuja superficialidade um jurista poderia ignorar. 
Para Schmitt (2005, 13), não existe norma que seja aplicada ao caos. Para uma ordem legal fazer sentido, uma situação normal deve existir e é o soberano quem decide quando esta situação normal realmente existe. Schmitt vai dizer que todo direito é situacional, a soberania produz e garante a situação na sua totalidade: o soberano tem o monopólio sobre a última decisão.

Assim dever ser definida a essência da soberania do Estado. Carl Schmitt afirma que a definição correta de soberania estatal é aquela que possui o monopólio da decisão ${ }^{1}$, ao contrário dos que afirmam que a soberania seria o monopólio da coerção ou da legislação. A exceção, segundo Schmitt, revela claramente a essência da autoridade do Estado. A autoridade prova que para se produzir a lei/direito não precisa do fundamento na lei/direito. Carl Schmitt defende que o a existência do estado é provada por sua superioridade sobre a validade da norma. A decisão é livre de todas as amarras normativas e se torna em seu sentido absoluta (SCHMITT, 2005, 12).

Schmitt apresenta que o Estado suspende a lei em seu direito de auto-preservação e que o que caracteriza a exceção é sua autoridade ilimitada, que significa a suspensão da existência inteira da ordem existente. Carl Schmitt evidencia que nessa situação resta clara o fato de que Estado continua enquanto o direito retrocede. Segundo Schmitt, a exceção é diferente da anarquia e do caos, porque mesmo na ordem, ela permanece.

\section{RESISTÊNCIA E ESTADO DE EXCEÇÃO}

O debate filosófico jurídico e político contemporâneo que Agamben trata no Estado de Exceção contempla a resistência diante da tradição jurídica, moderna e contemporânea da teoria e filosofia do direito constitucional, onde a tematização da resistência eleva-se num plano teórico metaconstitucional. Cito Agamben: "Discutiu-se muito, em especial nas assembléias constituintes, sobre a oportunidade de se inserir o direito de resistência no texto da constituição" (AGAMBEN, 2004, 23).

As analogias da resistência com o estado de exceção, diz o filósofo, encontra-se na posição simétrica dos argumentos que “... opõem os defensores da legalização do estado de exceção no texto constitucional ou numa lei específica aos juristas que consideram sua regulamentação normativa totalmente inoportuna" (AGAMBEN, 2004, 24).

Com essa observação, o filósofo nota que:

"[e]m todo caso, é certo que, se a resistência se tornasse um direito ou terminantemente um dever (cujo não cumprimento pudesse ser punido), não só a constituição acabaria por se colocar como um valor absolutamente intangível e totalizante, mas também as escolhas políticas dos cidadãos acabariam sendo juridicamente normalizadas" (AGAMBEN, 2004, 24). 
E em seguida, anota Agamben o ponto central desta questão filosófica de natureza jurídica e política: "De fato, tanto no direito de resistência quanto no estado de exceção, o que realmente está em jogo é o problema do significado jurídico de uma ação em si extra-jurídica." (AGAMBEN, 2004, 24).

No plano das teorias do direito constitucional, a questão filosófica jurídica da resistência assinala, segundo Agamben, que neste debate há duas teses opostas: "a que afirma que o direito deve coincidir com a norma e aquela que, ao contrário, defende que o âmbito do direito excede a norma" (AGAMBEN, 2004, 24), mas que em última análise, as duas posições opostas encontramse solidárias a uma mesma condição: "no excluir a existência de uma esfera da ação humana que escape totalmente ao direito" (AGAMBEN, 2004, 24).

Sobre a teoria do estado de exceção, podemos dizer que o sistema jurídico do Ocidente apresenta uma dupla estrutura, formada por dois elementos heterogêneos e, no entanto, coordenados: um elemento normativo e jurídico em sentido estrito - a potestas - e um elemento anômico e metajurídico - a auctoritas $^{2}$. O estado de exceção é o dispositivo que deve, em última instância, articular e manter juntos os dois aspectos da máquina jurídico-política, instituindo um limiar de indecibilidade entre anomia e nomos, entre vida e direito, entre auctoritas e potestas. Se baseia na ficção essencial pela qual a anomia - sob a forma da auctoritas, da lei viva ou da força de lei - ainda está em relação com a ordem jurídica e o poder de suspender a norma está em contato direto com

a vida.

(AGAMBEN,

2004 ,

Não se trata, e é evidente, de remeter o estado de exceção a seus limites de tempo e espaço definidos para reafirmar a primazia de uma norma e de direitos que, em última instância, têm nele o próprio fundamento.

"O retorno do estado de exceção efetivo em que vivemos ao estado de direito não é possível, pois o que está em questão agora são os próprios conceitos de 'estado 'e de 'direito'. Mas, se é possível tentar deter a máquina, mostrar sua ficção central, é porque, entre violência e direito, entre vida e norma, não existe nenhuma articulação substancial." (AGAMBEN, 2004, 131- 132)

\section{RESISTÊNCIA E ONTOLOGIA}

A resistência é pensada aqui a partir de sua natureza ontológica, situando-se em seu caráter potencial de ação: ética, jurídica, política ou de que natureza? Seria a prática pacífica uma resistência possível?

A resistência é contemplada à luz da filosofia jurídica e política de Giorgio Agamben, na sua relação ontológica pacífica com a proteção da vida nua na oikos, no interior das práticas de dominação biopolítica atual. (FELIPE, 2000; SINGER, 2004, 1995) 
A resistência, em seu caráter ontológico, pode ser considerada um movimento alternativo de oposição e negação das práticas de dominação e exploração das tecnologias da biopolítica sobre a vida nua.

E é assim que Agamben pensa criticamente categorias políticas e jurídicas em um novo contexto filosófico histórico, social, político, econômico e jurídico numa análise que leva a vida à política e a política à vida, num gesto que faz a contemporaneidade transparecer e revelar-se, através de sua própria face. Em seus estudos, elevando a política a seu status ontológico, o filósofo sinaliza o fracasso do seu confronto com as transformações que foram gradualmente esvaziando suas categorias e conceitos. E é considerando esse status ontológico da política que o pensamento de Agamben empreende uma ruptura com as formas totalitárias de dominação.

A pacificação que se pretende encontrar através de uma teoria de resistência no interior das práticas sociais, jurídicas e políticas, vem a encontro da própria necessidade contemporânea de práticas alternativas para sobrevivência, vivência, convivência e organização dos viventes terrestres.

Pensando a resistência a partir de sua natureza ontológica no interior da biopolítica para uma pacificação na oikos $^{3}$ contemporânea, uma resistência pacífica, que segundo Agamben, poderia traduzir-se como:

\footnotetext{
"A uma palavra não coercitiva, que não comanda e não proíbe nada, mas diz apenas ela mesma, corresponderia uma ação como puro meio que mostra só a si mesma, sem relação com um objetivo. E, entre as duas, não um estado original perdido, mas somente o uso e a práxis humana que os poderes do direito e do mito haviam procurado capturar no estado de exceção.” (AGAMBEN, 2004, 133)
}

A resistência pensada aqui é a resistência pacífica da vida nua: "O que deveria obter-se assim não é, todavia, uma vida animal nem uma vida humana, mas sim somente uma vida separada e excluída de si mesma, tão somente uma vida nua ." (AGAMBEN, 2006, 76)

\section{RESISTÊNCIA E VIDA NUA}

O conceito de vida nua tem caráter central nas pesquisas da filosofia de Giorgio Agamben. Na obra $O$ Aberto: $O$ Homem e $O$ Animal, por exemplo, Agamben faz uma genealogia do conceito de vida e o insere na problemática humanidade-animalidade no interior da história da filosofia.

O conceito de vida nua também tem análises que repercutem nas teorias bioéticas contemporâneas que consideram e refletem o tema da vida nua e em suas principais conseqüências do ponto de vista da economia e da política e em sua relação ontológica de resistência com o direito e com a sociedade como um todo (FELIPE, 2000; SINGER, 2004, 1995). 
O objetivo é investigar o conceito de estado de exceção e de resistência pacífica à luz dos estudos filosóficos de Agamben sobre o marco da biopolítica contemporânea e comparar com o estudo de Hannah Arendt sobre desobediência civil e violência realizados pela filósofa.

Nesta perspectiva, Agamben nos conduz a uma tematização do estado de exceção e da resistência, em relação à sua natureza ontológica e constitutiva no direito e na política.

Procuramos o que pode ser visto como uma aplicação do método da filosofia de Agamben. Tal método retoma algumas das formulações de Foucault acerca da arqueologia e genealogia conceitual. Investigar então, alguns dos motivadores da filosofia de Agamben, não deixa de ser uma forma de esclarecê-la. Entre estes: a análise de Hannah Arendt sobre o refugiado e a crítica aos direitos humanos; a questão do eu e da biopolítica de Michel Foucault; e, por fim, um autor de especial importância para Giorgio Agamben que é Walter Benjamin e suas análises sobre o direito e seu projeto crítico da violência, e da história;

Indo além das pretensões de Agamben, uma outra aplicação é repensar o próprio conceito de direito, que possa desativar ou desligar o dispositivo ou mecanismo que o liga à violência que o constitui. Podemos pautá-lo de forma que de um lado, preservando e respeitando a vida nua, também possa ele dar o passo além no sentido de uma recuperação da pura bios perpetrada como modus vivendi específico do humano pela, não somente filosofia grega, mas também pelo que antigamente seria chamado de civilização grega? E melhor ainda: pode ser a política pensada não mais na forma de uma relação ou relacionamento ou ligação de violência ao direito? Agamben em certa passagem diz que essa é a verdadeira crise da história contemporânea ao transtornar o modelo de sociabilidade da cidade para o campo ${ }^{5}$. Essa crise encaminhou-nos para as "barbáries", (se ainda faz sentido essa distinção), nunca antes vistas. Pode então haver uma resistência a isso? (os conflitos étnicos são a prova de que isso ainda não acabou). Pode mais que isso ser a emancipação do homem (forma-de-vida) na biopolítica contemporânea? Em suma: há ainda alguma forma possível de resistência que desative ou desligue o estado de exceção? (AGAMBEN, 2006, 76)

\section{RESISTÊNCIA, BIOPOLÍTICA E ESTADO DE EXCEÇÃO}

Desde a antiguidade clássica, o fim da cidade é viver segundo o bem. A finalidade da política é o bem viver dos homens entre si. Assim, Giorgio Agamben em Homo Sacer inicia sua pesquisa lembrando as palavras de Aristóteles, em Política:

\footnotetext{
"Primeiramente, consideremos qual é o objetivo de uma Cidade e quantas são as formas de governo pelas quais as sociedades humanas são reguladas. Dissemos, na primeira parte deste tratado, quando discutimos a administração doméstica e o poder do senhor, que o homem é por natureza um animal político. Por conseguinte, mesmo
} 
quando os homens não precisam de ajuda mútua, ainda assim têm o desejo de viver juntos; eles são levados a se associar por seus interesses em comum à proporção que conseguem alguma medida de bem-estar. Esta é certamente a principal finalidade, tanto do indivíduo quanto das Cidades, mas os homens também se unem simplesmente para viver (no que deve haver algum sublime elemento, desde que os infortúnios da existência estejam contrabalançados com as coisas boas). Vemos que os homens se associam e mantém conjuntamente uma comunidade política, e os homens se apegam à vida mesmo à custa de grande sofrimento, parecendo encontrar na vida uma doçura natural e felicidade."

O pensamento jurídico político contemporâneo encontra-se então desde a antiguidade preso à Cidade sendo este seu fim. A vida do homem está confinada a polis e este é seu bem. Mostrar o direito em sua não-relação com a vida e a vida em sua não-relação com o direito, o significa abrir entre eles um espaço para a ação humana que, há algum tempo, reivindicava para si o nome "política". E saber que ao lado do movimento que busca, a todo custo, mantê-los em relação, há um contramovimento que, operando em sentido inverso no direito e na vida, tenta, a cada vez separar o que foi artificial e violentamente ligado, o que se dá o nome de resistência. Assim, contemplamos que, no campo de tensões de nossa cultura, agem, portanto, duas forças opostas: uma que institui e que põe e outra que desativa e depõe $e^{6}$. Viver sob o estado de exceção significa fazer a experiência dessas duas possibilidades e, entretanto, tentar, incessantemente, interromper o funcionamento da máquina que está levando o Ocidente para a guerra civil mundial (AGAMBEN, 2004, 132).

Assim, como disse Foucault:

"que lá onde há poder há resistência. [...] Sim resistências, no plural, que são casos únicos: possíveis, necessárias, improváveis, espontâneas, selvagens, solitárias, planejadas, arrastadas, violentas, irreconciliáveis, prontas ao compromisso, interessadas ou fadadas ao sacrifício. [...] As resistências não se reduzem a uns poucos princípios heterogêneos; mas não é por isso que sejam ilusão, ou promessa necessariamente desrespeitada. Elas são o outro termo nas relações de poder; inscrevem-se nestas relações como o interlocutor irredutível. Também são, portanto, distribuídas de modo irregular: os pontos, os nós, os focos de resistência disseminam-se com mais ou menos densidade no tempo e no espaço, às vezes provocando o levante de grupos ou indivíduos de maneira definitiva, inflamando certos pontos do corpo, certos momentos da vida, certos tipos de comportamento." (FOUCAULT, 2005, 91-92)

Então retomando a pergunta anteriormente formulada, pergunta-se é possível uma forma de resistência:

“diante da força e da normalidade da exceção, e diante da imperiosa
normalidade da vida nua em que estamos ou fomos metidos? Ou então,
o que é possível fazer? O que nos resta fazer? Quem lê os livros de
Giorgio Agamben se sente interessado em saber mais e melhor o que
para ele é, ou são, 'o ser que vem', 'o ser humano que vem', 'a política
que vem', 'a ética que vem', 'a comunidade que vem'. Tudo o que vem
parece ter a ver com 'o messias que vem'. Cá e lá parece haver o
prenúncio ou anúncio de algo novo, de algo desejado, esperado em meio
ao desespero vivido, frente a uma normalidade pesada que não parece 
deixar nenhuma possibilidade senão uma vida nua." (ASSMANN, 2007, 4)

Podemos dizer que a política então sofreu um eclipse duradouro porque foi contaminada pelo direito, concebendo-se a si mesma, no melhor dos casos, como poder constituinte (isto é, violência que põe o direito). Ao contrário, verdadeiramente política é apenas aquela ação que corta o nexo entre violência e direito. E somente a partir do espaço que assim se abre, é que será possível colocar a questão a respeito de um eventual uso do direito após a desativação do dispositivo que, no estado de exceção, o ligava à vida. (AGAMBEN, 2004, 133)

Pois, afinal, como vimos, "o retorno do estado de exceção efetivo em que vivemos ao estado de direito não é possível, pois o que está em questão agora são os próprios conceitos de 'estado' e de 'direito"”. (AGAMBEN, 2004, 131)

\section{ESTADO DE EXCEÇÃO E VIOLÊNCIA}

Os dois elementos do conceito de ordem legal são dissolvidos em duas noções independentes que por sua vez testemunham sua independência conceitual. Ao contrário da situação normal, quando o momento autônomo da decisão retrocede ou recua ao mínimo, na exceção a norma é destruída (SCHMITT, 2005, 12).

A exceção permanece, todavia, acessível para a jurisprudência porque ambos os elementos, a norma e a decisão, permanecem como o padrão do jurídico.

De outro lado, para trazermos uma perspectiva comparada, é importante considerar a análise de Hannah Arendt em sua obra On Violence sobre os temas do poder, da autoridade e da violência, que foram levantados pelo debate acerca do estado de exceção em Agamben a partir de Carl Schmitt. Livro de Arendt que em alemão foi traduzido como Macht und Gewalt para destacar a ambiguidade do conceito.

On Violence (1969) é um livro independente e que consiste em uma versão expandida do artigo intitulado "Reflections of Violence" (1969) originalmente publicado em Journal of International Affairs e reimpresso em New York Review of Books (1969).

Trata-se de um ensaio extraordinário, que foi publicado também como capítulo da obra Crises of the Republic (1972), um dos últimos livros de Arendt e que, além do tema da violência, trata de desobediência civil, da mentira na política e de pensamentos sobre política e revolução.

Seria possível tentar fazer aqui um caminho para levar a todas as pequenas formas de digressões presentes nesse ensaio, muitas das quais fascinantes e poderiam até ser aqui lidas de maneira totalmente nova e que não obteríamos em qualquer lugar? ${ }^{7}$. 
Há tanto no ensaio de Arendt para falar. Por exemplo, sobre o presente na política brasileira e internacional ${ }^{8}$. Arendt tem muito a dizer e sobre uma série de temas incluindo o impeachment, violência institucional, intelectuais no poder, entre outros. São questões difíceis e importantes que estão na vanguarda da nossa política hoje, como ela faz previsões no livro e que, sem dúvida, faz dele um de seus ensaios mais populares e amplamente citados 9 .

Um dos motivos de ser amplamente citado se dá sobretudo em razão de sua distinção entre violência e poder, ${ }^{10}$ distinção que é única em seu tempo ${ }^{11}$ e se tornou incrivelmente importante. É também um dos seus ensaios mais criticados em torno de suas discussões sobre raça ${ }^{12}$. Há muitas coisas para dizer sobre o que ela diz sobre raça ${ }^{13}$. Arendt diz algumas coisas que têm sido vistas por muitas pessoas como errado ${ }^{14}$ e poderíamos falar sobre isso, mas é não é uma parte central do ensaio, então, por essa razão, vou comentar apenas com algumas notas sobre esse tema na minha pesquisa mais a frente ${ }^{15}$. Porém, a questão racial está lá e nós devemos estar cientes disso.

On Violence é dividido em três partes: a primeira parte pode ser chamada de violência e seus instrumentos, mas é mais do que isso, é também sobre o movimento estudantil da década de 1960 e por quê os movimentos estudantis da década de 1960 viraram-se para a violência e por que há uma glorificação crescente de violência em nossa cultura. A segunda parte do ensaio é realmente sobre poder e violência e desde aí começamos a ter alguns distinções analíticas: distinção o que é violência, o que é poder, o que é força, o que é autoridade, como a violência e o poder estão relacionados e separados uns dos outros e como eles trabalham. E, em seguida, a terceira parte do ensaio é sobre as causas e origens da violência, onde ela vai descer até as ciências sociais e biológicas que reduzem o homem ao animal, ciências que afirmam simplesmente que "somos todos violentos" dizendo que existem causas modernas únicas para o fato de se recorrer à violência.

Hannah Arendt compreende, por sua vez, o fenômeno da violência como denominador comum do século vinte. Para a autora, a violência, diferentemente do poder, da força e da coerção, necessita de implementos. Segundo Arendt, a violência sempre ocupou uma posição importante nos assuntos humanos, mas raramente foi objeto de consideração especial. Um exemplo dessa observação está na edição de 1969 da Enciclopédia de Ciências Sociais americana que não possui sequer a menção para o termo "violência”. Esta é uma indicação, segundo Hannah Arendt, de que a violência é considerada um fenômeno cotidiano e, por isso, negligenciada. Ela diz: "Ninguém interroga ou examina o que é óbvio para todo mundo"16 (ARENDT, 1969, 3).

De acordo com Hannah Arendt, nos registros do passado a violência foi considerada um fenômeno marginal. Para ela, todas as antigas verdades sobre a relação entre guerra e política, ou a respeito de violência e poder se tornaram inaplicáveis: “A Segunda Guerra Mundial não foi seguida pela paz, mas por uma Guerra Fria, e o estabelecimento de um complexo de trabalho industrialmilitar;" e também pela definição de Clausewitz na qual "a paz é a continuação da guerra por outros 
meios." Ela compara a violência dos estudantes negros ${ }^{17}$ com a violência dos trabalhadores dos Estados Unidos: "Força e violência provavelmente serão técnicas de controle social e persuasão bem sucedidas quando tiverem o apoio popular (ARENDT, 1969, 15)"18.

Segundo Paredes Goicochea (2021), o problema da transição da violência para a política no pensamento de Hannah Arendt se dá a partir da perspectiva de suas reflexões sobre a questão da guerra. Em primeiro lugar, o conceito de "desenvolvimento" é inadequado para compreender, em termos arendtianos, a passagem da violência para a política e, em segundo lugar, é necessário sugerir um entendimento alternativo dessa passagem através da análise de Arendt sobre a interpretação do tratamento grego e romano da Guerra de Tróia. Indicando, dessa forma, que em vez de tratar a transição como derivação ou conversão, Arendt destaca o papel da interrupção e da descontinuidade na transição da violência para a política.

Em On Violence, Arendt analisa a questão da violência no domínio da política e suas relações. Segundo ela, para a grande maioria dos autores a violência é considerada a mais flagrante forma de poder $^{19}$. Além disso, ela mesma se questiona sobre a possibilidade da violência desaparecer entre os Estados e se isto significaria o fim do poder. Seu propósito, todavia, consiste em diferenciar poder e violência. Para ela, poder e violência não são o mesmo. A diferença consiste em que o poder precisa de números e a violência não; a violência precisa de implementos, propiciados pela tecnologia. A forma extrema de poder é Todos contra Um; a forma extrema de violência é Um contra Todos (ARENDT, 1969, 38)." ${ }^{20}$ As diferenças entre violência, poder, autoridade e força não são apenas lógicas e gramaticais, mas históricas. As diferenças da violência precisam ser explicitados em dois domínios diferentes, o do povo e o do Estado. Para ela: "Nunca existiu governo exclusivamente baseado nos meios da violência" (ARENDT, 1969, 47). ${ }^{21}$ O poder é de fato a essência de todo governo, mas a violência não.

Keith Breen em seu artigo "Violence and Power: A Critique of Hannah Arendt on the political" afirma que, em contraste com a equação do realismo político do "político" com a dominação, Hannah Arendt entendeu o "político" como uma relação totalmente oposta ao uso da violência. Para Breen, torna-se claro que o desafio de Arendt ao realismo, como exemplificado por Max Weber, é bem sucedido por conta de uma redefinição duvidosa do "político" que é a imagem inversa da visão unilateral da política que ela esperava contestar. O questionamento dessa virada paradoxal leva a uma crítica da separação de Arendt entre violência e poder e, conseqüentemente, sua tentativa de isolar uma política de amizade de uma de hostilidade e coerção. No entanto, o realismo político não é assim afirmado. Para Breen (2007), o que é necessário, em vez disso, é uma visão do "político" que aceite o entrelaçamento de violência e poder, mas também enfatize os ideais normativos de moderação e cuidado. 
A ideia de justificação instrumental para meios violentos vista nos escritos de Hannah Arendt é um elemento central no argumento de Arendt contra teóricos como Georges Sorel e Frantz Fanon. Em On Violence é a distinção entre justificativas instrumentais e abordagens que enfatizam a 'legitimidade' da violência ou seu valor intrínseco. Todavia, segundo Finlay (2009), este não é o argumento suficiente para que Arendt enfrente as teorias rivais. Finlay afirma em seu artigo "Hannah Arendt's Critique of Violence" que a verdadeira distinção da visão de Arendt é vista quando nos voltamos para On Revolution e recolocamos os argumentos posteriores de On Violence no contexto de suas ideias sobre a separação entre revolução e libertação.

O compromisso de Arendt com a descoberta americana na política revolucionária de um meio que não precisa de outros fins para justificá-lo permite uma releitura de sua concepção de libertação como uma tentativa de imaginar uma violência que, embora taticamente instrumental, é ao mesmo tempo politicamente não instrumental. Mas, embora a visão de Arendt seja distinta, Finlay também destaca continuidades temáticas importantes com os escritos de Sorel e Walter Benjamin $^{22}$.

Para trazermos mais uma visão crítica, Ayça Çubukçu em“ Of Rebels and Disobedients: Reflections on Arendt, Race, Lawbreaking" afirma que Hannah Arendt valorizou sem precedentes o inesperado e o novo, mas em ensaios elaborados no final da rebelião dos anos 1960, lutou para conciliar essa avaliação com um desejo palpável de lei e ordem. De acordo com Çubukçu (2021), Arendt lamentou que a criminalidade tomou conta da vida americana, acusou a polícia de não prender criminosos o suficiente e acusou "a comunidade negra" de apoiar o que ela chamou de violência negra.

At once, she praised 'the white rebels 'of the student movement in the United States for their courageous acts of disobedience. This essay explores how differential Arendt's treatment of lawbreaking action was in an effort to understand how 'certain sections of the population 'in the United States could appear to stand for criminality rather than civil disobedience to her mind. It examines how Arendt's reflections on the ostensibly non-racial subjects of civil disobedience and lawbreaking were under written by racial, when not racist, ways of thinking. (ÇUBUKÇU, 2021).

Çubukçu também levanta uma questão mais ampla: para a extensão que o conceito de desobediência civil envolve limites, como esses limites são traçados para a exclusão de certos tipos de atores e suas reivindicações particulares na esfera pública? Ponderando essa questão por meio de Arendt, em sua teorização da desobediência civil, Çubukçu afirma que Arendt foi profundamente limitada pela fabulosa história de que os Estados Unidos são uma terra excepcional de liberdade e democracia no mundo.

Em defesa de Arendt, Steve Buckler (2007) busca mostrar que existe um método distinto e consistente no pensamento político de Hannah Arendt. Buckler argumenta que esse método constitui uma alternativa salutar e potencialmente desafiadora às abordagens convencionais da 
teoria política contemporânea. Em contraste com abordagens que adotam um ponto de vista infelizmente abstrato, resultante da insistência de que a teoria política responde formalmente às exigências da filosofia, Arendt adota um ponto de vista mais mediado e fenomenologicamente sensível. Rejeitando atribuições influentes a Arendt de um método baseado no uso da forma narrativa, Buckler identifica mediações-chave - epistemológicas e temporais - expressas em modulações da voz teórica que marcam a abordagem de Arendt como aquela que visa "salvar as aparências" do domínio público. Essas mediações são identificadas, exploradas e exemplificadas por referência a uma série de obras-chave de Arendt. Esta forma de caracterizar o método distinto de Arendt é então usada para lançar luz sobre a questão da dimensão normativa "ausente" em seu trabalho. Por fim, Buckler argumenta que Arendt vê a política como uma esfera potencialmente autorreguladora.

Continuando com as críticas, Elizabeth Frazer e Kimberly Hutchings (2008) tratam das implicações das críticas de Hannah Arendt a Frantz Fanon e as teorias da violência e da política associadas a sua influência para a compreensão da relação entre esses dois fenômenos. Fanon argumenta que a violência é um meio necessário para a ação política, e também é uma força ou energia orgânica. Arendt argumenta que a violência é inerentemente imprevisível, o que significa que o raciocínio final é, em qualquer caso, anti-político, e que é um erro profundo naturalizar a violência. Frazer e Hutchings avaliam os argumentos de Arendt e Fanon concluindo que, em sua rejeição bem fundada da naturalização da violência, a compreensão de Arendt da natureza corporificada da violência é menos perspicaz do que a de Fanon.

Sem dúvida, On Violence de Hannah Arendt é uma obra seminal no estudo da violência política. E é famosa por sua distinção entre poder e violência onde argumenta que esta última deve ser excluída da esfera política. Segundo Chad Kautzer, em "Political Violence and Race: A Critique of Hannah Arendt", embora isso possa tornar o texto de Arendt um recurso atraente para as críticas ao aumento da violência política hoje, devemos resistir à tentação desse argumento.

Kautzer (2019) identifica como as divisões e exclusões dentro da teoria de Arendt permitem que ela rejeite explicitamente a violência em um nível, enquanto confia implicitamente a forma enganosa de violência racial em um e constitutiva em outro. Em particular, Arendt deixa a violência legal e estatal presumida, mas não teorizada, focando sua crítica na ação dissidente, especialmente a do movimento Black Power. Qualquer análise que incorpore as distinções conceituais de Arendt é, portanto, suscetível de reproduzir uma teoria política que negligencia a violência do Estado a serviço do domínio branco, mas acusa aqueles que resistem a ela de violar a paz.

$\mathrm{Na}$ análise de Kautzer, o núcleo teórico do texto de Arendt é a distinção categórica que ela traça entre poder e violência e sua afirmação de que apenas o primeiro, o poder, é apropriado para a esfera política. Como seu amigo Walter Benjamin, cuja "Crítica da violência" (1921) também se 
tornou um texto influente nas análises da violência política, Arendt concentra sua crítica na instrumentalidade da violência. Essa instrumentalidade, ela argumenta, é, em princípio, inimiga da ação política e, portanto, qualquer tentativa de usar a violência como meio político deve ser criticada e resistida sem qualificação. Essa aparente exclusão categórica da violência da esfera política é intuitivamente atraente e, dado o mainstreaming da violência política hoje, o texto de Arendt pode parecer um recurso óbvio para as críticas contemporâneas.

Kautzer apresenta razões para resistir a essa tentação e identifica as maneiras pelas quais sua crítica da violência é cúmplice da lógica violenta de uma ordem diferente. Ele começa reconstruindo elementos da crítica de Benjamin, em parte porque a alternativa à violência que seu texto apresenta é bastante semelhante à de Arendt em aspectos importantes. De acordo com Kautzer, ambos procuram identificar uma forma de ação não violenta e não mediada ou não instrumental além da lei, e uma comparação de seus textos prova-se mutuamente iluminadora neste ponto. Apesar dessa semelhança, no entanto, seus textos são fundamentalmente opostos. Arendt nunca faz referência ao ensaio de Benjamin em On Violence ou outras obras. É possível que ela não soubesse disso, mas sua crítica é, de certa forma, estranhamente oposta. Enquanto Benjamin concentra sua crítica na violência da lei e do estado e busca identificar formas de ação dissidente que podem (e devem) minar ambos, Arendt concentra sua crítica na ação dissidente, particularmente do movimento Black Power, deixando a violência legal e estatal presumida, mas não teorizada. Essa presunção foi precisamente o alvo (e o ponto de partida) do ensaio de Benjamin e, portanto, descobrimos que sua tese central sobre a violência do direito tem força crítica contra o argumento de Arendt.

Kautzer (2019), após ter reconstruído componentes relevantes do argumento de Benjamin, volto-se para a crítica de Arendt à violência política, primeiro delineando as distinções entre as esferas política, social e privada, que estão explícitas em outras obras, mas operam apenas implicitamente em On Violence. Isso nos permite identificar como as divisões e exclusões no texto de Arendt permitem que ela repudie explicitamente a violência em um nível enquanto confia implicitamente em uma forma constitutiva e racializada de violência em outro, como já mencionado. Qualquer análise contemporânea que incorpore a crítica da violência de Arendt é, ele argumenta, suscetível a também reproduzir sua "perniciosa política racial", que negligencia a violência do estado (e da vigilância branca) enquanto acusa aqueles que resistem a ela de romper a paz. $\mathrm{O}$ que se segue é, portanto, nas própria palavras de Kautzer, "um conto de advertência".

Por outro lado, a partir de uma perspectiva pós-colonial, o artigo de Ratna Rapur (2020) “On violence, revolution and the self" examina a relação integral entre violência epistêmica e poder, especificamente no nível da concepção do indivíduo e sujeito na lei. A análise de Rapur destaca como os pressupostos que sustentam a noção de sujeito no individualismo liberal são constituídos 
por uma ordem racial e civilizacional normalizada, limitando a possibilidade de revolução. Ilustrando como esses limites operam por meio de uma discussão do ensaio On Violence de Hannah Arendt e seu tratamento da questão do assunto, o artigo de Rapur argumenta que a revolução requer uma concepção alternativa, ou não liberal, do assunto. Seu artigo aborda alternativas às noções préexistentes do sujeito liberal propostas por dois intelectuais pós-coloniais críticos, Frantz Fanon e seu contemporâneo, Ali Shari'ati. Essas articulações alternativas de subjetividade têm implicações para a forma como a violência e a revolução são entendidas, bem como para o avanço do projeto pós-colonial de desmantelamento do Império por meio do primeiro plano de epistemes não liberais $^{23}$.

\section{SOBRE O CONCEITO DE PODER E DESOBEDIÊNCIA CIVIL}

Em Crises of the Republic, Hannah Arendt inicia sua reflexão sobre a desobediência civil lembrando de um evento da Associação de Advogados na cidade de Nova York em 1970 que se colocava a seguinte questão: “A lei estará morta?"

Para Arendt, a motivação que teria levado a tal evento propor essa temática poderia ser o aumento de crimes nas ruas, ou a falta de credibilidade na lei - fato que ocorre nas modernas tiranias ou ainda poderia ser atribuída às campanhas de desobediência civil organizadas para se obter mudanças na legislação.

O fato é que essa discussão leva Arendt $(1972,52)$ a pensar a partir de uma relação entre o cidadão e a lei do ponto de vista moral constituído em uma sociedade do consentimento. Na literatura sobre o tema, Hannah Arendt destaca as referências a Sócrates e Thoreau, evidenciando o fato que ambos foram encarcerados o que seria um alegria para juristas porque poderia provar que a desobediência à lei apenas se justificaria se o contestador estivesse disposto a assumir a punição por seu ato.

Sobretudo nos Estados Unidos, predomina a figura do desobediente civil como um indivíduo que age de forma pessoal, levando a uma relação entre cidadão e lei do ponto de vista moral, ou seja, da consciência individual.

Há uma grande dificuldade dos juristas em explicar a compatibilidade do sistema legal com a desobediência civil, pois a lei não pode justificar a violação da lei (ARENDT, 1972, 53) uma questão de hierarquia e constitucionalidade das leis.

Para Arendt seria difícil e até ingênuo a condição de um homem que para testar a legitimidade de uma lei, viola essa mesma lei como o contestador civil. Alegar o motivo da 'mais alta lei' com uma grande convicção moral. Arendt procura distinguir o contestador civil e o criminoso assumir o castigo da transgressão. Fracasso teórico em se compreender e chegar a uma acordo sobre 
o fenômeno. Os juristas buscam justificar o fenômeno em termos de moralidade e legalidade e interpretam com base na objeção de consciência ou na constitucionalidade.

Para Arendt, a condição do problema não tem qualquer relação com essas anteriores, pois o contestação civil é coletiva, acontece em um grupo, e não de forma individual. Desobediência indireta, violar leis sem as achar passíveis de objeção em si, mas para protestar contra decretos e regulamentos injustos. Para ela, difícil de se justificar legalmente.

Necessidade de distinção entre objetores de consciência e contestadores civis. Os contestadores civis são minorias organizadas, delimitadas pela opinião comum (e não por interesses) e pela decisão de tomar posição contra a politica do governo, mesmo quando apoiada pela maioria, sua ação combina compromisso que dá crédito e convicção à opinião, não importando sua origem.

Arendt apresenta dois exemplos de desobediência civil na história:

1. Sócrates: relação moral do cidadão com a lei. Sócrates, durante seu julgamento nunca contestou as leis por elas mesmas, mas com o juízes. Sócrates se tivesse fugido, teria dado razão aos juízes e não a sua consciência.

2. Thoreau: protestou contra a injustiça das leis em si mesmas. Ele não debate no campo da moral do cidadão com a lei, mas no campo da consciência individual e do compromisso moral da consciência (ARENDT, 1972, 57).

\section{DESOBEDIÊNCIA CIVIL E CRIMINOSA}

Desobediência civil e criminosa à lei tornou-se fenômeno de massa, desprezo pela autoridade religiosa, secular moral ou política. São sinais gerais do nosso tempo (ARENDT, 1972, 67) e ver a desobediência civil como caso especial. Para os juristas, a lei é violada tanto pelo contestador civil quanto pelo criminoso e os advogados principalmente, tem facilidade nessa identificação por ser exercida em público.

A desobediência civil pode ser considerada uma indicação de perda significativa da autoridade da lei, mas a desobediência criminosa é consequência inevitável da desastrosa erosão da competência e do poder policial.

A desobediência civil aparece quando um número significativo de cidadãos se convence de que os canais normais de mudança já não funcionam e que as queixas não serão ouvidas nem que terão efeito, ou pelo contrário, o governo está em vias de efetuar mudanças e se envolve e persiste em modos de agir cuja legalidade e constitucionalidade estão expostas a graves dúvidas.

"Since disobedience and defiance of authority are such a general mark of our time, it is tempting to view civil disobedience as a mere special case. From the jurist's view-point, the law is violated by the civil, no less than the criminal, disobedient, and it is understandable that people, especially if they happen to be lawyers, 
should suspect that civil disobedience, precisely because it is exerted in public it at the root of the criminal variety" [...]. (ARENDT, 1972, 73)

A desobediência civil pode servir tanto para mudanças necessárias e desejadas como preservação ou restauração necessária e desejada do status quo. Em nenhum dos casos, a desobediência civil pode ser comparada a desobediência criminosa (ARENDT, 1972, 69).

Há um abismo de diferença entre o criminoso que evita os olhos do público e o contestador civil que toma a lei em aberto desafio (ARENDT, 1972, 75).

A primeira característica amplamente aceita pela literatura para o debate sobre a compatibilidade da desobediência civil com a legislação e com as instituições é que o criminoso comum, mesmo se fizer parte de uma organização criminosa, age em seu próprio benefício. Já o contestador civil, mesmo que dissidente da maioria, age em nome e para o bem de um grupo.

A segunda característica necessária amplamente aceita é a não-violência. O contestador civil aceita a estrutura estabelecida e a legitimidade geral do sistema de leis, a distinção entre o revolucionário e contestador civil.

\begin{abstract}
"Civil disobedience arises when a significant number of the citizens have become convinced either that the normal channels of change no longer function, and grievances will not be heard or acted upon, or that, on the contrary, the government is about to change and has embarked upon and persists in modes of action whose legality and constitutionality are open to grave doubt." (ARENDT, 1972, 74).
\end{abstract}

Citando John Locke em seu Second treatise of government, Arendt $(1972,77)$ afirma que a mudança faz parte do mundo: "Things of this world are in so constant a flux that nothing remains the same state."

Sobre a transformação, a mudança não é um fenômeno contemporâneo, é inerente a um mundo habitado e estabelecido por seres humanos que nele chegam pelo nascimento e pelos recém chegados jovens, e partem justamente quando adquirem experiência e a familiaridade que podem ser chamados de sábios nos caminhos do mundo. Mas são idosos, em vias de desaparecer do mundo e estão constantemente em choque com as tolices dos jovens, embora desempenhem um papel importante. Esta é a condição humana, a interrelação com jovens e idosos, sem a qual o mundo seria um tédio (ARENDT, 1972, 71).

O anseio do homem por mudança e sua necessidade de estabilidade sempre se equilibraram e toleram mutuamente, se distinguem em nosso vocabulário como sendo os progressistas e conservadores, nas facções.

Nenhuma civilização - artefato humano que abriga gerações sucessivas - teria sido possível sem a estrutura da estabilidade que proporcionasse o fluxo da mudança. Os sistemas legais que regulam nossa vida no mundo e nossas questões diárias uns com os outros são mais duradouros que os costumes e as tradições. Diante das transformações, a lei parece um força repressiva. 
The variety of such systems is great, both in time and space, but they all have one thing that justifies us in using the same word for phenomena as different as the Roman lex, the Greek nomos, the Hebrew torah - and this is that they were designed to insure stability. (There is other general characteristic of the law: that is not universally valid, but is either territorially bound or, as in the instance of Jewish law, ethnically restricted [...]. (ARENDT, 1972, 79)

A lei, seja como lex romana, nomos gregos e torah hebraica, - são planejadas para assegurar estabilidade. Não é universal, é territorial e étnica.

Nosso tempo, Arendt argumenta, experienciou níveis sem precedentes de mudança e também por que essas mudanças desafiam a ordem jurídica, desde o governo até a desobediência civil, e agora, conhece que as mudanças podem ser afetadas pela lei, as então chamadas ações legais que podem influenciar o modo como vivemos.

Para Arendt, a lei pode estabilizar e legalizar uma mudança já ocorrida, mas a mudança em si é uma ação extra-legal. A Constituição em si mesma oferece a possibilidade "quase-legal" de desafiar a lei através de sua transgressão. Mas estas violações não são atos de desobediência. A Suprema Corte, Arendt $(1972,80)$ diz, tem o direito de escolher entre os casos anteriores, e essa decisão é influenciada pela opinião pública.

O exemplo da Décima Quarta Emenda ${ }^{24}$ talvez seja instrutivo para explicar a relação entre a lei e a mudança. A Décima Quarta Emenda significou a constitucionalização de uma mudança que resultou do fim da Guerra Civil. Esta mudança, que não tinha sido aceita pelos estados do sul, o que teve como consequência a não implementação das medidas para a igualdade racial por centenas de anos.

Segundo Arendt, um dos exemplos mais contundentes ainda da inabilidade da lei de "forçar" uma mudança é a Décima Oitava Emenda, conhecida como "Proibição", e que foi rejeitada porque era "unenforceable". Por outro lado, a Décima Quarta Emenda foi finalmente "enforced" por uma ação legal da Suprema Corte. Arendt ainda enfatiza que, se alguém pode ainda argumentar que "sempre foi responsabilidade da Suprema Corte derrubar as leis que negavam a igualdade racial", o que a Corte fez foi apenas agir quando os movimentos de direitos civis, que eram evidentemente movimentos de desobediência civil, trouxeram mudanças drásticas nas atitudes de cidadãos negros e brancos (ARENDT, 1972, 81).

Era uma mudança ocorrida por parte dos movimentos de direitos civis, de desobediência. Assim, de acordo com Arendt, foi a desobediência civil e não a lei que proporcionou a abertura para o "Dilema Americano". Pela primeira vez na história, Arendt arrisca dizer, que a nação foi obrigada a reconhecer a enormidade do crime, não apenas da escravidão, mas da posse de escravos, responsabilidade que foi herdada de seus antepassados. 


\section{COMPATIBILIDADE DA LEI COM A DESOBEDIÊNCIA}

Para Arendt, com as rápidas mudanças de nosso tempo presente em relação as democracias modernas é possível pensar que a desobediência civil tem um papel e veio para ficar. Nessa hipótese, o grande problema para ela se dá referente às instituições de liberdade, se estas suportam esse ataque sem guerra civil ou revolução. Arendt $(1972,82)$ está interessada em saber com que conceito de lei a desobediência civil é compatível.

De acordo com a posição da literatura apresentada por Arendt, a Primeira Emenda estaria apta a receber este tipo de desafio, pois caberia a Suprema Corte decidir a teoria que seria estabelecida. Mas Arendt vê essa posição da literatura com problemas, pois a Primeira Emenda trata da liberdade de expressão e da imprensa, e estender a interpretação da liberdade da população em fazer protestos pacíficos e redigir petições para a "liberdade de ação" seria controverso.

De novo, para Arendt não se trata de "se ou/ ou o que estender" em relação à Primeira Emenda, mas sim, com qual conceito $^{25}$ (ARENDT, 1972, 83) de lei a desobediência civil seria compatível.

Em sua compreensão, Arendt afirma que em nenhum país o conceito de lei tem uma origem e substância tal $\operatorname{com}^{26}$ o nos Estados Unidos, algo ainda para ser completamente articulado e que segundo ela, se deu pela Revolução Americana. Algo como um espírito das leis tal como um nicho constitucional para o desenvolvimento da desobediência civil.

Arendt analisa que o compromisso do cidadão com a lei, sua "obrigação moral de cumprir a lei" vem do consentimento dado a estas leis ou por sendo o cidadão o próprio legislador.

That under the rule of law men are not subject to an alien will but obey only themselver - with the result, of course, that every person is at same time his own master and his own slave, and that what is seen as the original conflict between the citizen, the public good, and the self, pursuing his private happines, is internalized ${ }^{27}$.

O problema do consentimento tem sido debatido dentro da teoria política moderna por causa de sua origem fictícia: o contrato social. E é esse mesmo contrato social que está sob ataque.

Para tratar deste problema, Arendt $(1972,84)$ vai invocar Montesquieu e dizer:

If Montesquieu was right - and I believe he was - that there is such a thing as "the spirit of the laws", which varies from country to country and it different in the various forms of government, then we mat say that the consent, not in the very old sense of mere acquiescence, with its distinction between rule over willing subjects and rule over under willing ones, but in the sense of active support and continuing participation in all matters of public interest, is the spirit of American law (ARENDT, 1972, 85). 
Consentimento como apoio ativo e participação contínua em todos os assuntos de interesse público. Teoricamente, essa definição foi formulado como sendo o resultado de um contrato social, na sua forma mais comum: entre os cidadãos e o governo é facilmente denunciado como mera ficção. Todavia, observa Arendt, que não havia mera ficção na história pre-revolucionária americana, sendo que Locke, em sua formulação do contrato social observa: "In the beginning all the world was America".

Arendt traz em sua reflexão os três tipos de contrato social existentes. Segundo a autora, há um primeiro tipo de contrato, o qual temos o exemplo na Bíblia, um contrato de natureza teológica que o povo faz com seu Deus. Nesse tipo de contrato, as pessoas consentem por virtude em obedecer as leis quaisquer que sejam as apresentadas por Deus todo poderoso.

No segundo tipo de contrato, identificado por Hannah Arendt como o tipo hobbesiano, os indivíduos fazem um acordo com uma autoridade secular para a proteção de sua pessoa e de sua propriedade onde neste ele renuncia todos seus direitos e poderes. Arendt denomina este tipo de contrato de "vertical".

No terceiro tipo de contrato social, que é formulado por Locke apresenta um acordo entre todos os indivíduos da sociedade e, apenas de depois de constituído essa aliança, a sociedade estabelece o governo. Este tipo de contrato, denominado por Arendt de horizontal, limita o poder de cada indivíduo, mas deixa intacto o poder da sociedade:

All contracts, covenants, and agreements rest on lutuality, and the great advantage of the horizontal version of the social contract is that this mutuality binds each member to his fellow citizens. This is the only form of government in which people are bound together not through historical memories or ethnic homogeneity, as in the nation-state, and not through Hobbes's Leviathan, which "overawes them all" and thus united them, but through the strength of mutual promises. In Locke's view, this meant that society remains intact even if "the government is dissolved" or breaks its agreement with society, developing into a tyranny. Once established, society, as long as it exits at all, can never be thrown back into the lawlessness and anarchy of the state of nature. In Locke's words, "the power of every individual gave the society, when he entered into it, can never revert to the individuals again, as long as the society lasts, but will always remain in the community (ARENDT, 1972, 87).

Nesta terceira forma de contrato social, o consentimento significa o direito de divergir (ARENDT, 1972, 88).

Hannah Arendt também observa que no contrato original americano, índígenas e negros não estavam incluídos. O raciocínio então leva a concluir que se não estavam incluídos no contrato original, não eram cidadãos, ou seja, não faziam parte da sociedade e do governo ${ }^{28}$. 
Segundo Arendt, na concepção de consentimento moral está ligado o cumprimento de promessas. Para Arendt, a política é feita de promessas. A quebra das promessas significa o fracasso da autoridade.

No entendimento de Arendt, o espírito das leis é o princípio pela qual as pessoas agem e são inspirada a agir.

Podemos concluir que, segundo Hannah Arendt, o contestador civil se constitui de associações voluntárias que estão de acordo com as mais antigas tradições políticas americanas.

Podemos também apresentar, em conclusão, as seguintes características da desobediência civil de acordo com o pensamento de Arendt:

1. O contestador civil é diferente de objetor da consciência;

2. A desobediência civil como associação, isto é, coletiva;

3. Os juristas, "homens da lei:, veem com dificuldade sua existência;

4. Deve acontecer em público;

5. Em Arendt apresenta a necessidade de ser incorporada no sistema legal;

6. Deve ser institucionalizada;

7. A proposta de Arendt é a de colocar uma emenda na Constituição para sua garantia.

Por fim, para Arendt, os estados de emergência acontecem para nos "acordar". Acordar para a necessidade de realizar algo novo, a mudança.

\section{CONSIDERAÇÕES FINAIS}

O trabalho procurou analisar o conceito de estado de exceção teorizado por Giorgio Agamben e comparar com os estudos de Hannah Arendt sobre violência e resistência enquanto desobediência civil.

Para Agamben, o estado de exceção guarda em sua ontologia uma contiguidade com a resistência, por tratarem de fenômenos metajurídicos.

A resposta de Arendt ao debate trazido por Agamben nos propicia uma análise com a compatibilidade da resistência com o direito e a lei, sendo inclusive a posição defendida por ela, de que a Constituição deveria garantir este direito.

A violência é um tema debatido em torno do estado de exceção e do estado de direito, a qual emerge como violência criadora e violência conservadora do direito.

Hannah Arendt, aqui também, nos oferece uma abordagem mais interessante quando identifica o poder como algo diferente da violência. Ou seja, poder e violência não são sinônimos, embora o poder se utilize muitas vezes da violência como instrumento. 
Por fim, apresentar o debate sobre o estado de exceção e da resistência partindo de Agamben e fazendo uma leitura comparada com Arendt se mostrou interessante em razão da proposta arendtiana de distinguir os fenômenos poder, autoridade, força e violência.

Arendt nos traz esperança de pensar uma política que não seja feita por meios violentos nem que seja confundida com violência.

${ }^{1}$ Locke em Segundo Tratado do Governo Civil define o conceito de poder politico - poder civil - como o poder do magistrado de fazer leis com pena de morte e demais penalidades relacionadas a propriedade.

${ }^{2}$ Auctoritas e potestas são nomes inscritos por Agamben, segundo ele, por comodidade. No entanto, esses dois conceitos podem ser compreendidos, sobretudo a partir de Arendt, com o significado de "autoridade" e "poder".

${ }^{3}$ O melhor cenário para a oikos contemporânea, diz Agamben, é aquela que Guy Debord desenha em A Sociedade do Espetáculo.

${ }^{4}$ Aqui vida nua deve ser compreendida pela vida natural, a vida da natureza, tal como a forma de vida dos povos indígenas, a do meio ambiente, das florestas, dos rios, das montanhas, como sujeitos de direito e da ética.

${ }^{5}$ Com todas as consequiências para as ciências do homem que não perceberam essa transformação.

${ }^{6}$ De acordo com Benjamin em Zur kritik der Gewalt, violência criadora do direito (revolucionária) e violência conservadora do direito (o Estado e seu aparato).

7 "Parece que já se disse tudo o que poderia ser dito a respeito da compreensão arendtiana de poder. Por que, então, publicar outro texto a respeito do tema? Minha resposta tem dois elementos. Primeiro, porque é precisamente na discussão a respeito do conceito de poder que descobrimos o potencial crítico do pensamento de Arendt. Este potencial e sua geração ainda não foram obtidos pela análise de nossa ordem política moderna, e o fato de ele ter sido amplamente ignorado - e este é o segundo componente de minha resposta - está indubitavelmente relacionado à recepção limitada que a concepção arendtiana de poder tem encontrado". (VOLK, 2020).

${ }^{8}$ Nos Estados Unidos e no Brasil, políticos estão dando apoio ideológico à proliferação de gangues de rua fascistas e mobilizações de ódio. A National Rifle Association declarou recentemente que as "elites" acadêmicas, políticas e da mídia são as maiores ameaças domésticas da América, alimentando uma virada tática na cultura americana de armas que iguala a liberdade às armas de fogo e incentiva o treinamento militar em preparação para uma guerra civil. O ex-presidente dos Estados Unidos e outros também incentivaram repetidamente a violência contra jornalistas, oponentes políticos e outros grupos, orientando explicitamente a polícia a exercer mais violência contra suspeitos. Tendências semelhantes na normalização da violência política são evidentes em movimentos autoritários recentes em todo o mundo. (KAUTZER, 2019).

${ }^{9}$ De acordo com uma consulta feita durante a pesquisa às fontes do Google Scholar e da EBSCO, apenas desde 2020 são mais de 8.100 citações do ensaio On Violence, de Hannah Arendt.

${ }^{10}$ Dentre os inúmeros artigos e livros que tratam desta distinção arendtiana entre poder e violência, uma abordagem interessante do ponto de vista epistemológico é a feita por Ratna Rapur (2020), a partir da noção de violência epistêmica e sua relação com o poder e o sujeito. (KAPUR, 2020).

${ }^{11}$ Em contraste com a equação do realismo politico - do "político" com a dominação - Hannah Arendt entendeu o "político" como uma relação totalmente oposta ao uso da violência. (BREEN, 2007, 343-372)

${ }^{12}$ Hannah Arendt valorizou sem precedentes o inesperado e o novo, mas em ensaios elaborados no final da rebelião dos anos 1960, lutou para conciliar essa avaliação com um desejo palpável de lei e ordem. Ela lamentou que a criminalidade tomou conta da vida americana, acusou a polícia de não prender criminosos o suficiente e acusou "a comunidade negra" de apoiar o que ela chamou de violência negra. Imediatamente, ela elogiou "os rebeldes brancos" do movimento estudantil nos Estados Unidos por seus atos corajosos de desobediência. Algumas questões que a crítica de Çubukçu levanta: Como o tratamento diferenciado de Arendt da ação violadora da lei foi um esforço para entender como "certas seções da população" nos Estados Unidos podem parecer representar a criminalidade em vez da desobediência civil para sua mente? Como as reflexões de Arendt sobre os assuntos aparentemente não raciais de desobediência civil e transgressão da lei foram subscritas por formas raciais, quando não racistas, de pensar? (ÇUBUKÇU, 2021, 33)

13 "Many scholars concur with Maurizio Passerin d'Entrèves that Arendt 'cannot be characterized in terms of the traditional categories of liberalism, conservatism and socialism'. Nevertheless, James Martel has studied Arendt as an anarchist thinker. While I agree with Hutchings that one of the most remarkable things about Arendt's work is its capacity to unsettle comfort zones of ideological right/left thinking and the impossibility of incorporating it under any particular "ism"', in this essay, I am interested in exploring Arendt's conservative tendencies (rather 
than Arendt as $a$ conservative) in the context of the United States in the late 1960s, which she characterized as a 'revolutionary situation'." (ÇUBUKÇU, 2021, 34).

14 "I turn to Arendt's critique of political violence, first outlining her distinctions between the political, social, and private spheres, which are explicit in other works, but operate only implicitly in On Violence. This enables us to identify how the divisions and exclusions in Arendt's text allow her to explicitly disavow violence on one level while implicitly relying on a constitutive and racialized form of violence on another. Any contemporary analysis that incorporates Arendt's critique of violence is, I argue, susceptible to also reproducing her pernicious racial politics, which neglect state (and white vigilante) violence while charging those who resist it with breaching the peace. The following is thus intended as a cautionary tale." KAUTZER, 2019)

${ }^{15}$ Ao lado, tive a oportunidade de tratar do tema violência, racismo e injustiça estrutural no mundo pós-colonial em duas oportunidades durante o Estágio Pós-Doutoral: a primeira, apresentando um trabalho no V Simpósio Internacional de Filosofia da Dignidade Humana, do Grupo Internacional de Pesquisa em Direitos Humanos Raízes e Asas da UFMG, da Faculdade de Direito da Universidade Federal de Minas Gerais, e a segunda, com o trabalho "Violence and Structural Injustice in Post-Colonial World" aceito para o 26th IPSA World Congress of Political Science.

${ }^{16}$ Bernstein comenta esta observação de Arendt sobre a ausência de reflexão sobre o conceito de violência na década de 60 e 70 (BERNSTEIN, 3, 2011).

17 Sobre a questão dos negros nos Estados Unidos, a visão é controversa de Arendt, que a considera distinta da questão judaica, em termos de compreensão na esfera pública e privada (GINES, 2014; BERNSTEIN, 2011).

18 Sobre a interpretação do conceito de violência de Arendt em relação aos movimentos populares brasileiros de reivindicação de direitos na atualidade, ver a obra de MCMAHON intitulada' On 'real revolution 'and 'killing the lion': challenges for creative marginality in Brazilian labour struggles', em N.H.D. Geraghty and A.L. Massidda (eds.), Creative Spaces: Urban Culture and Marginality in Latin America.

19 Bernstein comenta esta afirmação de Arendt: Although Arendt tells us that there has been a reluctance to deal with violence as a phenomenon in its own right, there is nevertheless a consensus of theorists from the Left to Right to think that "violence is nothing more than the most flagrant manifestation of power." she quotes C. Wright Mills who starkly affirms: "All politics is a struggle for power; the ultimate power is violence." This declaration echoes "Max Weber's definition of the state as 'the rule of men over men based on the means of legitimate, that is allegedly legitimate violence." 11 This well entrenched paradigm of power, which has a long history, claims that power is the rule of an individual, group, or state over others. Power is understood to be power overIf this is the way we think of power, then it makes perfect sense to claim that the ultimate kind of power is violence. This is precisely the conception of power that Arendt challenges - and her point is not merely one of linguistic propriety. It goes to the very heart of her political thinking. Power and violence are not only distinguishable; they are antithetical. Where power reigns there is persuasion, not violence. And when violence reigns, it destroys power. she is critical of the question that many political theorists and philosophers have taken to be "the most crucial political issue": "Who rules Whom?" (BERNSTEIN, 2011, 6).

${ }^{20}$ Uma excelente abordagem sobre a compreensão arendtiana de poder e suas implicações para análise nas relações internacionais, ver a obra de LANG e WILLIAMS (2005) intitulada Hannah Arendt and International Relations: Readings Across the Lines.

${ }^{21}$ Além da obra On Violence, onde Arendt trata da relação entre violência e politica, sobre essa compreensão de uma forma mais aprofundada e a qual ela dedicou grande parte de sua vida, destaco aqui as suas obras: On Revolution (1963); The Origins of Totalitarianism (1966) The Promise of Politics (2005).

22 Sobre a crítica de Benjamin à violência e ao poder (RIBEIRO, 2020).

${ }^{23}$ Nesse sentido, "não é de forma alguma uma coincidência que o livro de James Scott, The Art of Not Being Governed, foi bem recebido entre acadêmicos e ativistas. Os críticos adotaram a descrição do antropólogo e cientista político dos EUA de comunidades que não apenas vivem sem estruturas estatais, mas também fogem ativamente da intervenção ou controle do Estado. Mais interessante do que o debate em si é a intensidade do posicionamento geral em relação ao estado. Enquanto alguns estudiosos acreditam que o Estado é necessário para garantir uma distribuição justa de bens, o estabelecimento da justiça e a aplicação de direitos, os estudiosos anarquistas celebram a ideia de coletivos que fogem do Estado e tendem a romantizá-los como espaços livres de dominação. Por meio do exemplo concreto da Inga, comunidade andina que não fugiu do Estado, mas responsabiliza o Estado-nação, apontamos problemas na romantização da ideia de zonas livres de Estado. Em vez disso, [...] como princípios e práticas como os de Buen Vivir podem ser lidos como resistência contra o capitalismo imperial intrusivo (DO MAR CASTRO VARELA \& TAMAYO ROJAS, 2020).

${ }^{24}$ Amendment XIV

Section 1. 
All persons born or naturalized in the United States, and subject to the jurisdiction thereof, are citizens of the United States and of the state wherein they reside. No state shall make or enforce any law which shall abridge the privileges or immunities of citizens of the United States; nor shall any state deprive any person of life, liberty, or property, without due process of law; nor deny to any person within its jurisdiction the equal protection of the laws.

Section 2.

Representatives shall be apportioned among the several states according to their respective numbers, counting the whole number of persons in each state, excluding Indians not taxed. But when the right to vote at any election for the choice of electors for President and Vice President of the United States, Representatives in Congress, the executive and judicial officers of a state, or the members of the legislature thereof, is denied to any of the male inhabitants of such state, being twenty-one years of age, and citizens of the United States, or in any way abridged, except for participation in rebellion, or other crime, the basis of representation therein shall be reduced in the proportion which the number of such male citizens shall bear to the whole number of male citizens twenty-one years of age in such state.

Section 3.

No person shall be a Senator or Representative in Congress, or elector of President and Vice President, or hold any office, civil or military, under the United States, or under any state, who, having previously taken an oath, as a member of Congress, or as an officer of the United States, or as a member of any state legislature, or as an executive or judicial officer of any state, to support the Constitution of the United States, shall have engaged in insurrection or rebellion against the same, or given aid or comfort to the enemies thereof. But Congress may by a vote of two-thirds of each House, remove such disability.

Section 4.

The validity of the public debt of the United States, authorized by law, including debts incurred for payment of pensions and bounties for services in suppressing insurrection or rebellion, shall not be questioned. But neither the United States nor any state shall assume or pay any debt or obligation incurred in aid of insurrection or rebellion against the United States, or any claim for the loss or emancipation of any slave; but all such debts, obligations and claims shall be held illegal and void.

Section 5 .

The Congress shall have power to enforce, by appropriate legislation, the provisions of this article.

${ }^{25}$ Destaque dado ao conceito é próprio mesmo do texto de Arendt na passagem de referência. 26

${ }^{27}$ Segundo Arendt, essa é solução de Kant e Rousseau para o problema da obrigação, mas que tem um defeito, segundo ela, do ponto de vista da consciência, que pode se colocar entre mim e mim mesma.

${ }^{28}$ Com todas as implicações que isso possa significar.

\section{REFERÊNCIAS BIBLIOGRÁFICAS:}

AGAMBEN, Giorgio. Lo Abierto - El Hombre y El Animal. Valencia, Pre-Textos, 2005.

AGAMBEN, Giorgio. Estado de Exceção. São Paulo: Boitempo. 2004.

ARENDT, Hannah. On Revolution. New York: Viking Press, 1963

ARENDT, Hannah. The Origins of Totalitarianism. New York: Harcourt, 1966.

ARENDT, Hannah. On Violence. New York: Harcourt, 1969.

ARENDT, Hannah. "Reflections on Violence.” Journal of International Affairs, vol. 23, no. 1, 1969, pp. 1-35.

ARENDT, Hannah. Crises of the Republic. New York: Harcourt, 1972. 
ARENDT, Hannah. The Promise of Politics. New York: Schocken, 2005.

ARENDT, Hannah. Macht und Gewalt. München: Piper Verlag, 2014.

ARISTÓTELES. The Works of Aristotle, Volume II. Chicago: Encyclopedia Britannica, Inc. 1952. ASSMANN, Selvino J. Apresentação. Florianópolis: UFSC, 2007.

BENJAMIN, W. Gesammelten Schriften. 17 Band. Frankfurt am Main: Suhrkamp Verlag, 1991.

BERNSTEIN, Richard J. "Hannah Arendt's Reflections on Violence and Power". Iris, III 5 April 2011, p. 3-30. (Firenze University Press).

BERNSTEIN, Richard J. Why read Hannah Arendt now? Cambridge, MA: Polity, 2018.

BREEN, Keith. "Violence and Power: A Critique of Hannah Arendt on the political." Philosophy \& Social Criticism, vol. 33, no. 3, May 2007, pp. 343-372

BUCKLER, Steve. "Political Theory and Political Ethics in the Work of Hannah Arendt". Contemporary Political Theory 6, 461-483 (2007).

ÇUBUKÇU, Ayça. “Of Rebels and Disobedients: Reflections on Arendt, Race, Lawbreaking”. Law Critique 32, 33-50, 2021.

DEBORD, Guy. A Sociedade do Espetáculo. Rio de Janeiro: Contraponto. 1997.

DO MAR CASTRO VARELA, Maria, \& TAMAYO ROJAS, Caroline. "Epistemicide, postcolonial resistance and the state". Postcolonial Studies, 1-15, 2020.

FANON, Frantz. Pele Negra, Máscaras Brancas. Tradução Sebastião Nascimento e colaboração de Raquel Camargo. São Paulo: UBU Editora, 2020.

FELIPE, Sonia T. Por uma Questão de Princípios. Florianópolis: Fundação Boiteux. 2002.

FINLAY, Christopher J. "Hannah Arendt's Critique of Violence.” Thesis Eleven, vol. 97, no. 1, May 2009, pp. 26-45.

FOUCAULT, Michel. História da Sexualidade I: A Vontade de Saber. Rio de Janeiro: Edições Graal. 2005.

FOUCAULT, Michel. Vigiar e punir. Rio de Janeiro: Edições Graal. 2006.

FRAZER, Elizabeth, HUTCHINGS, Kimberly. "On Politics and Violence: Arendt Contra Fanon". Contemporary Political Theory 7, 90-108 (2008).

FRY, Karin. "Hannah Arendt and the War in Iraq". Philosophical Topics, Vol. 39, No. 2, Hannah Arendt (FALL 2011), pp. 41-51. (University of Arkansas Press).

GINES, Kathryn T., Hannah Arendt and the Negro Question. Indiana: Indiana University Press, 2014. 
GOLDONI, Marco; MCCORKINDALE, Christopher (ed.) Hannah Arendt and the Law. Oxford: Hart Publishing, 2012.

HOLTAWAY, Jess. "Power v. Violence: How can contemporary art create a 'space of appearance' and generate social change?" In: Kinna R, Whiteley G, ed., Cultures of Violence: Visual Arts and Political Violence. London: Routledge, Taylor \& Francis Group. 2020. p. 100-117.

HOBBES, Thomas. Leviatã. Tradução: João Paulo Monteiro e Maria Beatriz Nizza da Silva. São Paulo: Martins Fontes, 2003.

JIMÉNEZ-MARTÍNEZ, César. “The Instrumental Mediated Visibility of Violence": The 2013 Protests in Brazil and the Limitations of the Protest Paradigm". The International Journal of Press/Politics, (2020).

KAPUR, Ratna. “On violence, revolution and the self”. Postcolonial Studies, 1-19, 2020.

KAUTZER, Chad. "Political Violence and Race: A Critique of Hannah Arendt." CLCWeb: Comparative Literature and Culture 21.3 (2019).

LANG, Anthony F.; WILLIAMS, Jr. John (ed.). Hannah Arendt and International Relations: Readings Across the Lines. New York, 2005.

LARIOS, Joe. "Arendt, Levinas, and the Justification of Violence in advance." Arendt Studies, Philosophy Documentation Center, 2021.

LLOYD, David. "From the Critique of Violence to the Critique of Rights". Critical Times 1 April 2020; 3 (1): 109-130.

LOCKE, John. O Segundo Tratado sobre o Governo Civil. Tradução: Magda Lopes e Marisa Lobo da Costa. Editora Vozes: Petrópolis, 1994.

MCMAHON, L. 'On 'real revolution' and 'killing the lion': challenges for creative marginality in Brazilian labour struggles", in N.H.D. Geraghty and A.L. Massidda (eds.), Creative Spaces: Urban Culture and Marginality in Latin America (London: Institute of Latin American Studies, 2019).

PAREDES GOICOCHEA, Diego. "On the Transition From Violence to Politics in Hannah Arendt's Thought”. Tópicos (México) [online]. 2021, n.60, pp.269-292.

PONTEL, E. Estado de exceção e a governamentalidade da vida: a guerra como paradigma político. Veritas. Jul-Set2019, Vol. 64 Issue 3, p1-30. 30p.

NASCIMENTO, Milton Meira do. "Dentro e fora da lei." Jornal de Resenhas, Vol. III. São Paulo: Discurso Editorial. 2002.

RAWLS, John. Theory of Justice. Cambridge: Harvard University Press, 1999.

RIBEIRO, Karla Pinhel. "Violência e Poder em Hannah Arendt”. Cadernos Arendt, v. 1, n. 1, 2020.

RIBEIRO, Karla Pinhel. "Zur kritik der Gewalt de Benjamin”. Cadernos Benjamin, n. 25, Edição Jul-Dez, 2020. 
ROYER, Christof. "The Conundrum(s) of Political Violence." Humanity: An International Journal of Human Rights, Humanitarianism, and Development, vol. 11 no. 3, 2020, p. 370-381.

SANTOS, Silvia Gombi. Em Busca de um Lugar no Mundo: o conceito de violência em Hannah Arendt. São Paulo: Editora Perspectiva, 2011.

SCHMITT, Carl. Political theology. Chicago: University of Chicago Press, 2005.

SINGER, Peter. Libertação animal. Porto Alegre, São Paulo: Lugano. 2004.

SINGER, Peter.(ed.) Compendio de Ética. Madrid: Alianza Editorial. 1995.

US CONSTITUTION. Legal Information Institute. Cornell Law School. https://www.law.cornell.edu/constitution/amendmentxiv

VOLK, Christian. "The Decline of Order: Hannah Arendt and the Paradoxes of the Nation-State." In Politics in Dark Times: Encounters with Hannah Arendt, edited by Seyla Benhabib, 172-97. Cambridge: Cambridge University Press, 2010.

VOLK, Christian. "Hannah Arendt e a crítica ao poder". Cadernos Arendt, V. 2, n.1, 2020. 